\section{NEUROSCIENCE}

\section{White matter matters in autism}

A genetic mutation that causes defects in the insulation of neurons may contribute to the cognitive deficits seen in autism and other neuropsychiatric disorders.

Pratik Mukherjee of the University of California in San Francisco and his colleagues used magnetic resonance imaging to study the brains of 23 children with a deletion in a region of the genome associated with such disorders.

The authors found that in these children, the white matter, which helps signals travel between neurons, was structurally defective. The children scored lower on non-verbal IQ tests (such as visual recognition and memory) than those without the genetic deletion.

J. Neurosci. 34, 6214-6223 (2014)

\section{CRYOSPHERE}

\section{Tipping point for Antarctic melting}

Loss of a crucial 'plug' of ice in Antarctica could result in massive sea-level rise, with the discharge of a huge ice sheet.

The Wilkes Basin in East Antarctica contains enough ice to raise global sea levels by 3-4 metres. Anders Levermann and Matthias Mengel at the Potsdam Institute for Climate Impact Research in Germany used topographic data and simulations of ice dynamics to investigate the basin's vulnerability to climate change. They found that if a key plug of ice - equivalent to 80 millimetres of global sea-level rise - were to be lost

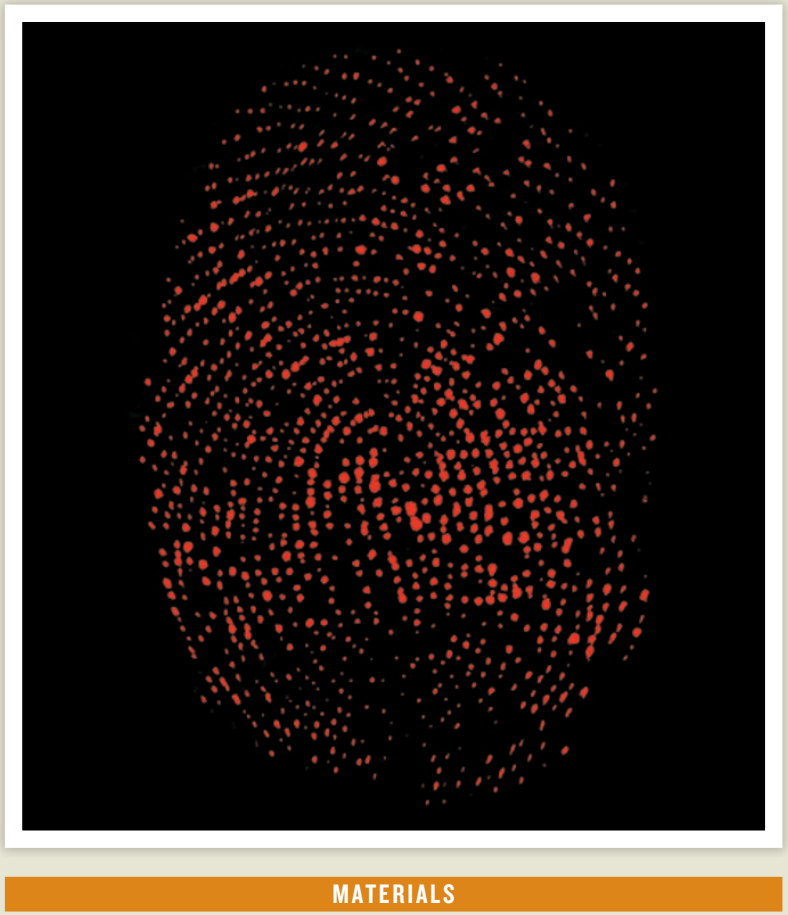

\title{
Sweat-pore fingerprint
}

A polymer that is sensitive to sub-nanolitre volumes of water could be used to map sweat pores for fingerprint analysis.

Jong-Man Kim and Chan Woo Lee at Hanyang University in Seoul and their colleagues developed a thin film made of caesium polydiacetylene that changes from blue to red in the presence of water. The authors found that a fingertip pressed on the blue film produced a pattern of red dots (pictured) that coincided with sweat pores and was visible using an optical microscope.

The sensor technology could be used to identify people by their fingerprint even if only a small part of it was visible, the authors say.

Nature Commun. 5, 3736 (2014)

from the region, the Wilkes Basin ice sheet would be destabilized, creating a selfsustaining discharge of the whole basin over 10,000 years and leading eventually to global sea-level rise on the metre scale.

However, the ice sheet would remain stable if the equivalent of less than 60 millimetres of sea-level rise were lost. Nature Clim. Change http://dx.doi. org/10.1038/nclimate2226 (2014)

VIROLOGY

\section{Antibodies for Middle East virus}

Two independent teams have identified antibodies that can vanquish a deadly virus first reported in the Middle East.

Since it appeared in 2012, the Middle East respiratory syndrome (MERS) coronavirus has caused disease in at least 261 people and killed nearly
100 in Asia, North Africa and Europe as of 26 April, according to the World Health Organization. There are no vaccines or drugs for the virus.

Wayne Marasco at the Dana-Farber Cancer Institute in Boston, Massachusetts, and Ralph Baric at the University of North Carolina in Chapel Hill and their team identified seven human antibodies that recognize different parts of a key MERS coronavirus protein and prevent it from recognizing and entering human cells in culture.

Another team, led by Linqi Zhang at Tsinghua University in Beijing, identified two more neutralizing antibodies. The molecules recognize different portions of the same MERS coronavirus protein and work together to block the virus's ability to infect cells.

If the antibodies prove to be safe and effective for human use, they could be administered to prevent or treat MERS coronavirus infections, both teams say.

Proc. Natl Acad. Sci. USA http://doi.org/smr (2014); Sci. Transl. Med. 6, 234ra61 (2014)

\section{Hunger marks offspring's genome}

Male mice that are undernourished while in the womb sire offspring with an increased risk of metabolic disorders such as diabetes.

Josep Jiménez-Chillarón at the Sant Joan de Deu Hospital in Barcelona, Spain, and his colleagues underfed pregnant mice and found that male offspring had a chemical modification on the Lxra gene, which regulates fat metabolism in the liver.

This 'epigenetic' change was transmitted through the offspring's sperm to the next 